\title{
A Single Dose of Dietary Nitrate Increases Maximal Knee Extensor Angular Velocity and Power in Healthy Older Men and Women
}

\author{
Andrew R. Coggan, PhD, ${ }^{1,2, *, \bullet}$ Richard L. Hoffman, MS, ${ }^{1}$ Derrick A. Gray, BS, ${ }^{1}$ \\ Ranjani N. Moorthi, MD, ${ }^{3}$ Deepak P. Thomas, MD, ${ }^{4}$ Joshua L. Leibowitz, MD, ${ }^{4,5}$ \\ Dakkota Thies, AAS, ${ }^{5}$ and Linda R. Peterson, MD, ${ }^{4,5}$
}

\begin{abstract}
'Department of Kinesiology, ${ }^{2}$ Department of Cellular and Integrative Physiology, and ${ }^{3}$ Department of Internal Medicine, Indiana University—Purdue University Indianapolis. ${ }^{4}$ Department of Medicine and ${ }^{5}$ Department of Radiology, Washington University School of Medicine, St. Louis, Missouri.
\end{abstract}

\begin{abstract}
*Address correspondence to: Andrew R. Coggan, PhD, Department of Kinesiology, Indiana University—Purdue University Indianapolis, IF 101C, 250 University Boulevard, Indianapolis, IN 46112. E-mail: acoggan@iupui.edu
\end{abstract}

Received: February 13, 2019; Editorial Decision Date: June 9, 2019

Decision Editor: Anne Newman, MD, MPH

\begin{abstract}
Background: Aging results in reductions in maximal muscular strength, speed, and power, which often lead to functional limitations highly predictive of disability, institutionalization, and mortality in elderly adults. This may be partially due to reduced nitric oxide (NO) bioavailability. We, therefore, hypothesized that dietary nitrate $\left(\mathrm{NO}_{3^{-}}\right)$, a source of $\mathrm{NO}$ via the $\mathrm{NO}_{3^{-}} \rightarrow$ nitrite $\left(\mathrm{NO}_{2^{-}}\right) \rightarrow \mathrm{NO}^{-}$enterosalivary pathway, could increase muscle contractile function in older subjects.

Methods: Twelve healthy older (age $71 \pm 5$ years) men and women were studied using a randomized, double-blind, placebo-controlled, crossover design. After fasting overnight, subjects were tested 2 hours after ingesting beetroot juice containing or devoid of $13.4 \pm 1.6 \mathrm{mmol}$ $\mathrm{NO}_{3-}$. Plasma $\mathrm{NO}_{3^{-}}$and $\mathrm{NO}_{2-}$ and breath $\mathrm{NO}$ were measured periodically, and muscle function was determined using isokinetic dynamometry. Results: $\mathrm{NO}_{3^{-}}$ingestion increased $\left(p<.001\right.$ ) plasma $\mathrm{NO}_{3^{-}}$, plasma $\mathrm{NO}_{2^{-}}$, and breath $\mathrm{NO}$ by $1,051 \% \pm 433 \%, 138 \% \pm 149 \%$, and $111 \% \pm$ $115 \%$, respectively. Maximal velocity of knee extension increased $(p<.01)$ by $10.9 \% \pm 12.1 \%$. Maximal knee extensor power increased $(p$ $<.05)$ by $4.4 \% \pm 7.8 \%$.

Conclusions: Acute dietary $\mathrm{NO}_{3-}$ intake improves maximal knee extensor angular velocity and power in older individuals. These findings may have important implications for this population, in whom diminished muscle function can lead to functional limitations, dependence, and even premature death.
\end{abstract}

Keywords: Nitric oxide, Nitrite, Isokinetic dynamometry, Blood pressure

Aging is accompanied by a progressive reduction in the maximal strength, speed, and especially power of skeletal muscle. These age-related physiological changes often lead to functional limitations that are highly predictive of disability, institutionalization, and mortality in the elderly population $(1,2)$. Numerous factors account for this decline in muscle function, with age-related changes in the size, properties, and neural control of muscle all playing a role (3).

Another important factor contributing to this age-related decrease in muscle contractility may be a reduction in nitric oxide
(NO) bioavailability. Although initially identified as a vasodilator, that is, as "endothelium-derived relaxing factor", NO is in fact a key cellular signaling molecule with pleiotropic effects in many tissues. These include skeletal muscle, wherein among other effects NO significantly increases the rate of force development, maximal shortening velocity, and maximal power during concentric contractions (4). With aging, however, whole-body NO production decreases, as evidenced, for example, by a progressive decline in the plasma concentrations of its downstream metabolites, nitrite $\left(\mathrm{NO}_{2-}\right)$ and 
nitrate $\left(\mathrm{NO}_{3-}^{-}\right)$(5). In skeletal muscle itself, there is a dramatic decrease in interstitial $\mathrm{NO}_{2-}$ and $\mathrm{NO}_{3}$ - concentrations (6), as well as a decline in the activity of the neuronal form of NO synthase (7), the primary isoenzyme within muscle responsible for the synthesis of NO from l-arginine, $\mathrm{O}_{2}$, and nicotinamide adenine dinucleotide phosphate. These changes are accompanied by an age-related reduction in flow-mediated vasodilation (8), a hallmark indicator of NO bioavailability. In turn, the latter (ie, flow-mediated vasodilation) has been shown to correlate positively with muscular power and physical functioning in older men and women (9). Taken together, these data suggest that decreased NO production may contribute to the age-associated decline in muscle contractile properties and hence in functional capacity.

Along with the $\mathrm{NO}$ synthase pathway, $\mathrm{NO}$ can also be produced in the body via chemical reduction of $\mathrm{NO}_{3-}$ to $\mathrm{NO}_{2-}$ and hence to $\mathrm{NO}(10)$. This $\mathrm{NO}_{3-} \rightarrow \mathrm{NO}_{2^{-}} \rightarrow \mathrm{NO}$ pathway is facilitated by bacterial nitrate reductases in the mouth and/or mammalian nitrate reductases (eg, xanthine oxidase) in the tissues, and is accelerated at low $\mathrm{pO}_{2}$ and low $\mathrm{pH}$, conditions typical of resting and especially contracting muscle (11). Numerous studies in recent years have therefore examined the effects of dietary $\mathrm{NO}_{3}$ - supplementation on various physiological responses mediated by $\mathrm{NO}$, for example, muscle blood flow (12). This includes studies of the effects of $\mathrm{NO}_{3-}$ ingestion on performance during aerobic exercise in older individuals $(13,14)$, including those with cardiovascular disease (15-17). To date, however, no study has determined the influence of dietary $\mathrm{NO}_{3-}$ on muscle contractile function in older humans.

We have previously demonstrated that $\mathrm{NO}_{3-}$ supplementation increases maximal knee extensor angular velocity and power in healthy younger and middle-aged subjects $(18,19)$ and in patients with heart failure (20). We have also found that it increases maximal cycling power and optimal pedaling rate in athletes (21). However, it cannot simply be assumed that dietary $\mathrm{NO}_{3-}$ will be equally efficacious in older individuals. For example, in rodents the effects of dietary $\mathrm{NO}_{3}$ - appear to be more prominent in fast- versus slowtwitch muscle $(11,22)$, and some (23), but not all (24), studies of humans have found that aging results in a reduction in the percentage of fast-twitch muscle fibers. Alternatively and/or in addition, a decrease in the ability of salivary glands to concentrate $\mathrm{NO}_{3^{-}}(25)$ or more rapid destruction of $\mathrm{NO}$ due to increased production of reactive oxygen species (26) could limit the beneficial effects of dietary $\mathrm{NO}_{3-}$ in older persons.

The purpose of this study was to test the hypothesis that by enhancing $\mathrm{NO}$ production, acute dietary $\mathrm{NO}_{3}$ - supplementation would improve maximal knee extensor angular velocity and power in healthy older men and women. If so, this could have important implications for this population, in whom diminished muscle function can contribute significantly to functional limitations, disability, dependence, and even death $(1,2)$.

\section{Methods}

\section{Subjects and Experimental Design}

Twelve nondiabetic men and women $\left(n=6\right.$ each) with mean $\left({ }_{ \pm} S D\right)$ age, height, body mass, and body mass index of $71 \pm 5$ years, $1.71 \pm$ $0.10 \mathrm{~m}, 75.2 \pm 12.2 \mathrm{~kg}$, and $25.7 \pm 3.5 \mathrm{~kg} / \mathrm{m}^{2}$, respectively, were studied using a double-blind, placebo-controlled, crossover design. The first six were studied in St. Louis, with the remaining six studied in Indianapolis using essentially identical procedures. All were in good health, as assessed by physical examination and standard blood chemistries, but only three exercised regularly (one by cycling, one by lifting weights, one via group exercise classes). Prescription medications used by the subjects included antihypertensives $(17 \%)$, statins $(17 \%)$, antidepressants (33\%), glaucoma medications $(33 \%)$, and intestinal mobility inhibitors $(17 \%)$. Baseline knee extensor isometric and isokinetic peak torque (see later) averaged $82 \% \pm 12 \%$ and $81 \% \pm 13 \%$ of expected, respectively (27).

Exclusion criteria included age below 65 or above 79 years or history of significant cardiovascular (eg, stage II or greater hypertension, heart failure, and myocardial infarction/ischemia), renal (estimated glomelular filtration rate $<60 \mathrm{~mL} / \mathrm{min} / 1.73 \mathrm{~m}^{2}$ or $61-90 \mathrm{~mL} /$ $\mathrm{min} / 1.73 \mathrm{~m}^{2}$ and albumin:creatinine ratio $>30$ ), or liver disease (serum glutamic-oxaloacetic transaminase/serum glutamic pyruvic transaminase $>2 \mathrm{x}$ normal), anemia (hematocrit $<30 \%$ ), or any other contradiction to strenuous exercise. Those taking phosphodiesterase inhibitors (eg, sildenafil) were excluded, as these can potentiate NO effects (28). Those taking proton pump inhibitors, antacids, xanthine oxidase inhibitors, or on hormone replacement therapy were also excluded, as these can affect reduction of $\mathrm{NO}_{3-}$ and $\mathrm{NO}_{2-}(29,30)$.

Approval for the study was obtained from the Human Research Protection Office at Washington University in St. Louis and the Human Subjects Office at Indiana University, and written, informed consent was obtained from each subject.

\section{Experimental Protocol}

Subjects reported to the Clinical Research Unit at Washington University in St. Louis or the Clinical Research Center at Indiana University Purdue University Indianapolis in the morning after avoiding high $\mathrm{NO}_{3}$ - foods (eg, arugula, beets, spinach) for the previous 24 hours and any food, caffeine, and alcohol for the previous 12 hours. During this period, they also refrained from chewing gum, brushing their teeth, or using an antibacterial mouthwash, as these can block reduction of $\mathrm{NO}_{3-}$ to $\mathrm{NO}_{2-}$ by oral bacteria (31). After measurement of seated heart rate and blood pressure and the level of NO in breath (NIOX VERO; Circassia Pharmaceuticals, Mooresville, NC), an intravenous catheter was placed and a baseline blood sample was obtained for subsequent measurement of plasma $\mathrm{NO}_{3-}$ and $\mathrm{NO}_{2-}$ concentration using high performance liquid chromatography (ENO-30; Eicom USA, San Diego, CA). The subject then ingested $140 \mathrm{~mL}$ of concentrated beetroot juice (BRJ; Beet It Sport; James White Drinks, Ipswich, UK) either containing $13.4 \pm 1.6 \mathrm{mmol}$ of $\mathrm{NO}_{3^{-}}$or an equal volume of $\mathrm{BRJ}$ from which the $\mathrm{NO}_{3-}$ had been removed by the manufacturer. The subject then rested quietly, with additional measurements of heart rate, blood pressure, breath $\mathrm{NO}$, and plasma $\mathrm{NO}_{3-}$ and $\mathrm{NO}_{2-}$ obtained 1 and 2 hours after BRJ ingestion. Muscle contractile function was then measured during the third hour post-BRJ ingestion as described later, with final measurements of hemodynamics and $\mathrm{NO}_{3}-\mathrm{NO}_{2-}-$ NO obtained 10 minutes postexercise. Subjects were then fed a light meal and released from the Clinical Research Unit/Clinical Research Center. After a 1-2 weeks washout period, they returned for second visit during which they were "crossed over" to the other treatment and all of the earlier described procedures repeated.

\section{Measurement of Muscle Contractile Function}

The contractile properties of the quadriceps muscle group were measured using an isokinetic dynamometer (Biodex System 4 Pro; Biodex Medical Systems, Shirley, NY) as previously described in detail (18). Briefly, after alignment of the lateral femoral epicondyle of the subject's dominant leg with the axis of rotation of the 
dynamometer, they performed maximal knee extensions at angular velocities of (in order) $0,1.57,3.14,4.71$, and $6.28 \mathrm{rad} / \mathrm{s}(0,90$, 180,270 , and $\left.360^{\circ} / \mathrm{s}\right)$. Subjects executed $3-4$ maximal efforts at each velocity and were allowed 2 minutes of rest after each set of contractions. Isometric testing was conducted at a knee joint angle of $1.22 \mathrm{rad}\left(70^{\circ}\right)$. Peak torque was expressed relative to body mass (ie, in $\mathrm{Nm} / \mathrm{kg}$ ), after which peak power (in $\mathrm{W} / \mathrm{kg}$ ) at each velocity was calculated by multiplying peak torque by velocity. Maximal knee extensor power $(P \max$, in $\mathrm{W} / \mathrm{kg}$ ) and angular velocity ( $\omega$ max, in $\mathrm{rad} / \mathrm{s}$ ) were then determined by fitting an inverted parabola to the peak power-velocity relationship (18). After the final rest period, subjects performed 50 maximal knee extensions at $3.14 \mathrm{rad} / \mathrm{s}$ to determine the effects of dietary $\mathrm{NO}_{3-}$ on fatigue resistance during repetitive muscular contractions, as this is also an important predictor of the risk of disability and/or mortality in older individuals (2). Subjects were encouraged throughout the test to exert themselves maximally during each of the 50 knee extensions.

\section{Statistical Analyses}

On the basis of our previous research (18-21), changes in markers of $\mathrm{NO}$ bioavailability (ie, plasma $\mathrm{NO}_{3}-\mathrm{NO}_{2-}$ and breath $\mathrm{NO}$ ) and in muscle function during the torque-velocity (power-velocity) test were considered primary outcomes. Other outcomes were considered secondary.

Normality of data distribution was tested using the D'AgostinoPearson omnibus test. Hemodynamic, plasma $\mathrm{NO}_{3-}$ and $\mathrm{NO}_{2-}$, breath $\mathrm{NO}$, peak torque, and peak power data from the placebo and $\mathrm{NO}_{3-}$ trials were compared using two-way (treatment $\times$ time or treatment $\times$ velocity) repeated measures analysis of variance. Post hoc testing was performed using the Šidák multiple comparison procedure. Absolute values and changes in wmax and Pmax were compared between treatments using two-sample paired and one-sample $t$ tests, respectively. Effect sizes were calculated as partial eta squared $\left(\eta_{p}^{2}\right)$. Pearson product correlations were calculated to explore the relationship between changes in plasma $\mathrm{NO}_{3_{-}}, \mathrm{NO}_{2_{-}}$, or breath $\mathrm{NO}$ and changes in wmax and Pmax. $p$ Value of less than .05 was considered significant. Statistical analyses were performed using GraphPad Prism, version 8.01 (GraphPad Software Inc, La Jolla, CA).

\section{Results}

All subjects completed the entire study protocol. One individual experienced mild-to-moderate diarrhea during both the placebo and $\mathrm{NO}_{3-}$ trials, but no other adverse effects were observed.

\section{Primary Outcome Variables}

Values for plasma $\mathrm{NO}_{3-}$ and $\mathrm{NO}_{2-}$ and breath $\mathrm{NO}$ are shown in Figure 1. There were significant main effects for time $\left(\eta_{p}^{2}=0.74\right.$, $p<.0001)$ and treatment $\left(\eta_{p}^{2}=0.89, p<.0001\right)$ and a significant time $\times$ treatment interaction effect $\left(\eta_{p}^{2}=0.74, p<.0001\right)$ for plasma $\mathrm{NO}_{3-}$. Post hoc testing indicated that plasma $\mathrm{NO}_{3-}$ was higher $(p<.0001)$ in the $\mathrm{NO}_{3-}$ trial at 1 and 2 hours following BRJ ingestion and also at 10 minutes postexercise. Similar results were observed for plasma $\mathrm{NO}_{2-}$, with time $\left(\eta_{p}^{2}=0.39, p=.0011\right)$, treatment $\left(\eta_{p}^{2}=0.54, p=.0018\right)$, and time $\times$ treatment interaction effects $\left(\eta_{p}^{2}=0.36, p=.0019\right)$ all being significant. Plasma $\mathrm{NO}_{2-}$ was significantly different between trials at 2 hours $(p=.016)$ and 10 minutes postexercise $(p<.0001)$. Finally, for breath NO, there were significant main and interaction effects (time: $\eta_{p}^{2}=0.53, p=.0003$; treatment: $\eta_{p}^{2}=0.69, p=.0013$; interaction: $\left.\eta_{p}^{2}=0.45, p=.0004\right)$,
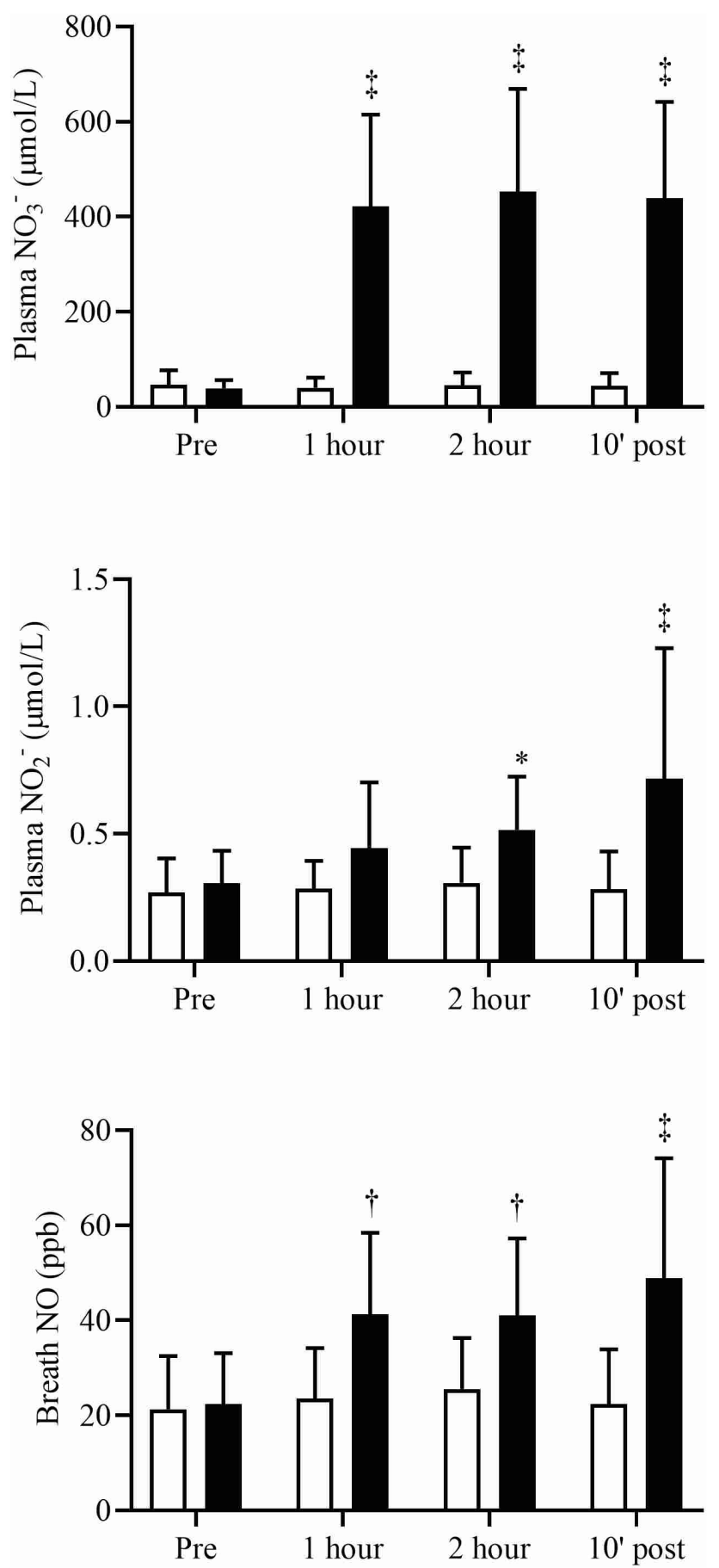

Figure 1. Effects of dietary $\mathrm{NO}_{3-}$ on plasma $\mathrm{NO}_{3-}, \mathrm{NO}_{2_{-}}$, and breath $\mathrm{NO}$ in healthy 65-79 years old men and women $(n=12) .10^{\prime}$ post, 10 minutes postexercise. Nitrate trial significantly higher than placebo trial: ${ }^{*} p<.05,+p$ $<.001, \mp p<.0001$.

with breath $\mathrm{NO}$ being higher in the $\mathrm{NO}_{3}$ - versus the placebo trial at 1 and 2 hours postingestion and 10 minutes postexercise $(p=.0002$, $p=.0009$, and $p<.0001$, respectively).

Data for peak knee extensor torque and power are shown in Table 1. For peak torque relative to body mass, there was a significant effect for velocity $\left(\eta_{p}^{2}=0.99, p<.0001\right)$, a nonsignificant effect for treatment $\left(\eta_{p}^{2}=0.03, p=.60\right)$, and a nonsignificant interaction effect $\left(\eta_{p}^{2}=0.17, p=.075\right)$. For peak torque relative to isometric 
torque, there was a significant effect for velocity $\left(\eta_{p}^{2}=1.00, p<\right.$ $.0001)$, a nonsignificant effect for treatment $\left(\eta_{p}^{2}=0.22, p=.25\right)$, and a significant interaction effect $\left(\eta_{p}^{2}=0.23, p=.018\right)$. On the basis of post hoc testing, peak torque relative to isometric torque was significantly higher $(p=.0004)$ in the $\mathrm{NO}_{3-}$ versus the placebo trial at the highest velocity of $6.28 \mathrm{rad} / \mathrm{s}$. Finally, for peak power relative to body mass, there was a significant effect for velocity $\left(\eta_{p}^{2}=1.00\right.$, $p<.001)$, a nonsignificant effect for treatment $\left(\eta_{p}^{2}=0.06, p=.36\right)$, and a significant interaction effect $\left(\eta_{p}^{2}=0.37, p=.0003\right)$. Post hoc testing indicated that $\mathrm{NO}_{3}$ - ingestion significantly increased $(p<$ .0001) peak power relative to body mass at $6.28 \mathrm{rad} / \mathrm{s}$.

Data for absolute and relative changes in $\omega \max$ and $P$ max are shown in Figures 2 and 3, respectively. Dietary $\mathrm{NO}_{3}$ - ingestion increased $\omega \max$ from $10.1 \pm 2.0$ to $11.2 \pm 2.1 \mathrm{rad} / \mathrm{s}\left(\eta_{p}^{2}=0.49\right.$, $p=.0078$ ), that is, by $1.1 \pm 1.1 \mathrm{rad} / \mathrm{s}$ (Figure 2 , top panel; $\eta_{p}^{2}=0.49$, $p=.0079$ ) or $10.9 \% \pm 12.1 \%$ (Figure 2 , bottom panel; $\eta_{p}^{2}=0.47$, $p=.0099)$. Correspondingly, Pmax increased from $3.90 \pm 1.22$ to $4.04 \pm 1.19 \mathrm{~W} / \mathrm{kg}\left(\eta_{p}^{2}=0.32, p=.042\right)$, that is, by $0.14 \pm 0.21 \mathrm{~W} / \mathrm{kg}$

Table 1. Effects of Dietary $\mathrm{NO}_{3-}$ on Peak Knee Extensor Torque and Power as a Function of Velocity in Healthy 65-79 Years Old Men and Women.

\begin{tabular}{|c|c|c|c|c|c|c|}
\hline & \multirow[b]{2}{*}{ Trial } & \multicolumn{5}{|c|}{ Angular velocity (rad/s) } \\
\hline & & 0 & 1.57 & 3.14 & 4.71 & 6.28 \\
\hline \multirow[t]{2}{*}{ Peak torque $(\mathrm{Nm} / \mathrm{kg})$} & Placebo & $1.94 \pm 0.36$ & $1.42 \pm 0.30$ & $1.02 \pm 0.26$ & $0.75 \pm 0.24$ & $0.60 \pm 0.21$ \\
\hline & Nitrate & $1.90 \pm 0.40$ & $1.38 \pm 0.27$ & $0.99 \pm 0.23$ & $0.75 \pm 0.21$ & $0.65 \pm 0.20$ \\
\hline \multirow[t]{2}{*}{ Peak torque ( $\%$ of isometric) } & Placebo & $100.0 \pm 0.0$ & $72.9 \pm 5.0$ & $52.3 \pm 7.6$ & $38.2 \pm 8.0$ & $30.7 \pm 7.1$ \\
\hline & Nitrate & $100.0 \pm 0.0$ & $73.1 \pm 7.3$ & $53.2 \pm 11.1$ & $40.4 \pm 11.7$ & $34.5 \dagger \pm 9.8$ \\
\hline \multirow[t]{2}{*}{ Peak power (W/kg) } & Placebo & $0.00 \pm 0.00$ & $2.04 \pm 0.45$ & $3.28 \pm 0.79$ & $3.77 \pm 1.09$ & $3.50 \pm 1.43$ \\
\hline & Nitrate & $0.00 \pm 0.00$ & $1.96 \pm 0.40$ & $3.22 \pm 0.70$ & $3.84 \pm 0.98$ & $3.82 \ddagger \pm 1.29$ \\
\hline
\end{tabular}

Note. Values are mean $\pm S D$ for $n=12$.

Nitrate trial significantly higher than placebo trial.: $\nmid p<.001 ; \ddagger p<.0001$.
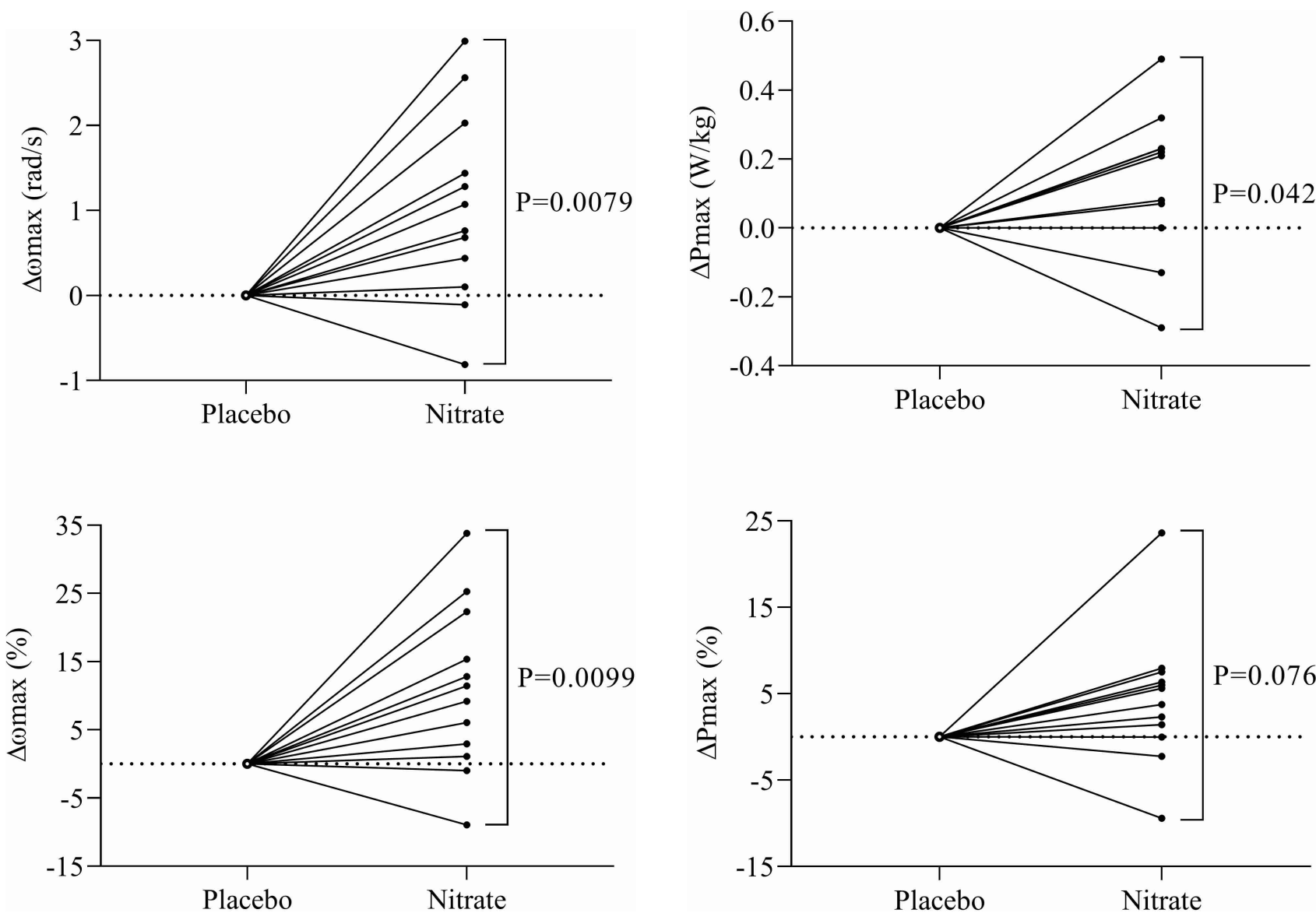

Figure 2. Absolute (top panel) and relative (bottom panel) changes in the maximal angular velocity of knee extension ( $\omega$ max) in response to acute dietary $\mathrm{NO}_{3-}$ ingestion in healthy $65-79$ years old men and women $(n=12)$.

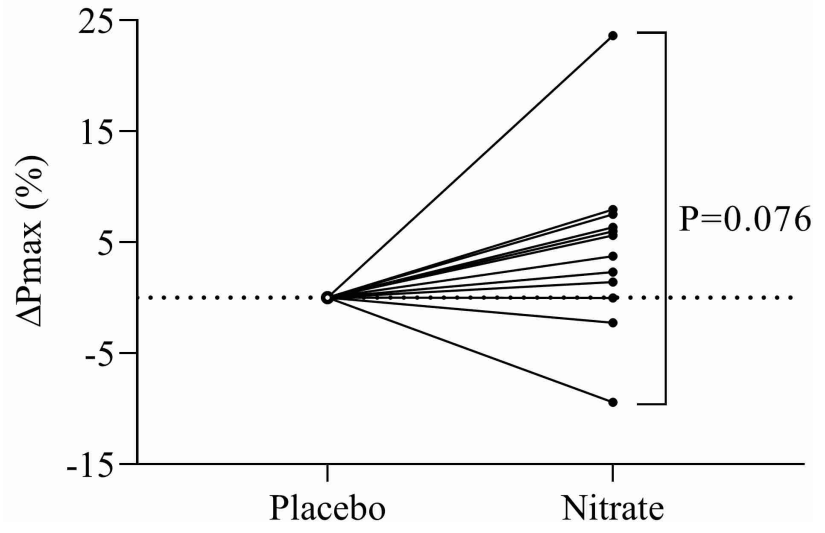

Figure 3. Absolute (top panel) and relative (bottom panel) changes in the maximal power of knee extension ( $P$ max) in response to acute dietary $\mathrm{NO}_{3}$ ingestion in healthy 65-79 years old men and women $(n=12)$. 
(Figure 3, top panel; $\eta_{p}^{2}=0.32, p=.042$ ) or $4.4 \% \pm 7.8 \%$ (Figure 3, bottom panel; $\left.\eta_{p}^{2}=0.26, p=.076\right)$.

The absolute or relative changes in $\omega \max$ were not significantly correlated with changes in plasma $\mathrm{NO}_{3-}$ or $\mathrm{NO}_{2-}$ (data not shown) but were significantly correlated with changes in breath $\mathrm{NO}$ $(r=.58-0.75 ; p<.01-.05)$. On the other hand, no significant correlations were found between changes in $P \max$ and changes in plasma $\mathrm{NO}_{3-}-\mathrm{NO}_{2-}$ or breath $\mathrm{NO}$ (data not shown).

\section{Secondary Outcome Variables}

There were no significant differences between the placebo and $\mathrm{NO}_{3}$ - trials in peak power $(3.20 \pm 0.84$ vs. $3.16 \pm 0.76 \mathrm{~W} / \mathrm{kg}$; $\left.\eta_{p}^{2}=0.01, p=.73\right)$, average power $(0.99 \pm 0.24$ vs. $1.03 \pm 0.27 \mathrm{~W} /$ $\left.\mathrm{kg} ; \eta_{p}^{2}=0.08, p=.18\right)$, or total work $(32.3 \pm 8.8$ vs. $34.0 \pm 9.9 \mathrm{~J} / \mathrm{kg}$; $\eta_{p}^{2}=0.20, p=.12$ ) relative to body mass, or in fatigability (ie, ratio of work during last $1 / 3$ rd vs. first $1 / 3$ rd; $0.47 \pm 0.11$ vs. $0.46 \pm 0.11$; $\eta_{p}^{2}=0.07, p=.38$ ) during the 50 contraction fatigue test.

Heart rate and blood pressure data are provided in Table 2. For heart rate, there was a significant main effect for time $\left(\eta_{p}^{2}=0.48\right.$, $p=.0054)$, but not for treatment $\left(\eta_{p}^{2}=0.10, p=.064\right)$ or for time $\times$ treatment interaction $\left(\eta_{p}^{2}=0.01, p=.98\right)$. Systolic blood pressure also differed over time $\left(\eta_{p}^{2}=0.30, p=.0079\right)$, but the treatment $\left(\eta_{p}^{2}=0.01, p=.79\right)$ and interaction $\left(\eta_{p}^{2}=0.15, p=.15\right)$ effects were nonsignificant. Diastolic blood pressure, on the other hand, did not vary with time $\left(\eta_{p}^{2}=0.07, p=.28\right)$ but did vary with treatment $\left(\eta_{p}^{2}=0.20, p=.035\right)$. The time $\times$ treatment interaction effect was not significant $\left(\eta_{p}^{2}=0.04, p=.73\right)$.

\section{Discussion}

The purpose of this study was to test the hypothesis that acute dietary $\mathrm{NO}_{3-}$ supplementation would improve maximal knee extensor angular velocity and power in healthy older men and women. In keeping with our previous studies (18-21), we found that acute $\mathrm{NO}_{3-}$ ingestion increased $\omega \max$ and $P \max$ in older subjects by approximately $11 \%$ and approximately $4 \%$, respectively. Although modest in size, these changes are potentially clinically significant. Between the ages of 25 and 72 years, for example, the maximal velocity of unloaded knee extension has been reported to decrease by $27 \%$, or by approximately $0.6 \%$ per year on average (32). Across a similar age range, peak knee extensor power was found to decrease by approximately $0.3 \%$ per year in men and approximately $0.6 \%$ per year in women (33). The dietary $\mathrm{NO}_{3-\text {-induced increases }}$ in maximal knee extensor angular velocity and power observed in this study are therefore functionally equivalent to acutely reversing the effects of several decades of aging. Although greater attention is generally paid to age-related declines in muscle strength, age-related reductions in muscle speed have been found to play a greater role in explaining functional deficits in older individuals (34). Similarly, decreases in muscle power, that is, the product of speed and force, with aging have been reported to be a more powerful predictor of functional decline than decreases in force (strength) alone (3). The distinct improvements in $\omega \max$ and $P \max$ that we observed following acute $\mathrm{NO}_{3}$ - ingestion could thus have a significant impact on the independence and quality of life of older individuals. Testing this hypothesis, however, will require determining whether the acute responses observed in this study are maintained with continued ingestion of $\mathrm{NO}_{3^{-}}$, as well as whether such changes translate into long-term improvements in functional abilities and activities of daily living, especially in older subjects more representative of the general aging population than the healthy individuals that we studied.

Although the dietary $\mathrm{NO}_{3}$-induced changes in muscle function observed in the present study may be clinically significant, they are in fact similar in magnitude to those we have previously found for healthy young and middle-aged subjects $(18,19)$. This observation runs counter to our hypothesis that older subjects would benefit more from dietary $\mathrm{NO}_{3-}$. This is presumably because the healthy older men and women in this study were not overtly NO-deficient. Their baseline breath NO levels, for example, were comparable to those we have found previously in younger subjects $(18,19)$. Their baseline plasma $\mathrm{NO}_{3-}$ and $\mathrm{NO}_{2-}$ concentrations were also similar to those we have measured previously (19). In contrast, breath NO levels tended (ie, $p=.07$ ) to be lower in the middle-aged patients with heart failure that we studied previously (21), and compared to the present subjects they exhibited a threefold greater relative improvement in Pmax following acute $\mathrm{NO}_{3-}$ ingestion (ie, $13 \%$ vs. $4 \%$ ). Additional studies will therefore be required to determine whether dietary $\mathrm{NO}_{3}$ - is even more effective at enhancing muscle contractile function in older men and women in whom NO bioavailability is more clearly reduced. It should be noted, however, that the differential response described earlier might also be due to a difference in muscle fiber type distribution between the two groups (11), that is, an increase in the percentage of fast-twitch fibers in patients with heart failure (35) versus a possible decrease in healthy aging subjects (23).

In contrast to the significant improvements observed during the force-velocity testing, acute $\mathrm{NO}_{3}$ - ingestion had no effect on peak power, average power, total work, or fatigability during the 50 contraction fatigue test. In keeping with this, Kelly and colleagues (13) previously reported that $\mathrm{NO}_{3}$ - supplementation does not alter muscle energetics during high-intensity knee extensor exercise in healthy older men and women. Similarly, Siervo and colleagues (14) found that dietary $\mathrm{NO}_{3-}$ does not improve time to exhaustion during an incremental cycle ergometer exercise test in healthy older

Table 2. Effects of Dietary $\mathrm{NO}_{3-}$ on Heart Rate and Blood Pressure in Healthy 65-79Years Old Men and Women

\begin{tabular}{|c|c|c|c|c|c|}
\hline & \multirow[b]{2}{*}{ Trial } & \multicolumn{4}{|c|}{ Time of measurement } \\
\hline & & Pre-ingestion & $1 \mathrm{~h}$ post-ingestion & $2 \mathrm{~h}$ post-ingestion & 10 min post-exercise \\
\hline \multirow[t]{2}{*}{ Heart rate (beats/min) } & Placebo & $69 \pm 14$ & $68 \pm 12$ & $67 \pm 12$ & $73 \pm 11$ \\
\hline & Nitrate & $67 \pm 12$ & $67 \pm 10$ & $65 \pm 12$ & $72 \pm 14$ \\
\hline \multirow[t]{2}{*}{ Systolic blood pressure $(\mathrm{mmHg})$} & Placebo & $130 \pm 18$ & $126 \pm 14$ & $127 \pm 13$ & $128 \pm 13$ \\
\hline & Nitrate & $134 \pm 22$ & $127 \pm 23$ & $121 \pm 18$ & $126 \pm 20$ \\
\hline \multirow[t]{2}{*}{ Diastolic blood pressure $(\mathrm{mmHg})$} & Placebo & $72 \pm 12$ & $71 \pm 10$ & $71 \pm 10$ & $71 \pm 9$ \\
\hline & Nitrate & $70 \pm 8$ & $69 \pm 10$ & $69 \pm 11$ & $66 \pm 10$ \\
\hline
\end{tabular}

Note. Values are mean $\pm S D$ for $n=12$. 
subjects. More research into the effects of $\mathrm{NO}_{3}$ - supplementation on exercise capacity in this population is warranted. It is possible, for example, that older individuals may require a higher dose of $\mathrm{NO}_{3-}$ to elicit improvements in performance during high-intensity exercise. Nonetheless, our data suggest that muscle contractile properties are more sensitive/responsive to $\mathrm{NO}_{3-}$ intake than resistance to fatigue during repeated contractions.

Along with the absence of changes in fatigue resistance during intense exercise, there were also no significant differences in blood pressure between the placebo and $\mathrm{NO}_{3-}$ trials. This observation differs from a number of previous studies (36), including some of older subjects $(37,38)$. There is evidence, however, that aging may attenuate the vasodilatory effects of dietary $\mathrm{NO}_{3-}$ (39). Furthermore, there was a tendency for the change in systolic blood pressure to be greater after $\mathrm{NO}_{3-}$ ingestion $\left(-9 \pm 12\right.$ vs. $\left.-3 \pm 9 \mathrm{mmHg} ; \eta_{p}^{2}=0.41, p=.12\right)$, suggesting that the lack of difference in absolute blood pressure may represent a type II error. Nonetheless, as with the fatigue test data discussed earlier, our divergent results with respect to the impact of $\mathrm{NO}_{3}$ - intake on muscle contractile function and on blood pressure indicate that the former is more likely to show beneficial effects in older subjects.

There are a number of limitations to the present investigation. As indicated earlier, the small sample size may have precluded us from detecting statistically significant changes in blood pressure in response to dietary $\mathrm{NO}_{3-}$. Furthermore, although we recently hypothesized that dietary $\mathrm{NO}_{3-}$ enhances contractile function by altering $\mathrm{Ca}^{2+}$ release and/or sensitivity in muscle (40), this study does not speak to this question. Along the same lines, although we have demonstrated that acute $\mathrm{NO}_{3}$ - intake is efficacious in enhancing maximal knee extensor angular velocity and power in older subjects, the optimal dose for improving this or other important physiological responses in this population remains to be identified. Further research will also be required to determine whether the acute responses that we have observed are maintained, or perhaps even magnified, by continued supplementation, and/or whether they are also evident in less healthy older subjects. Finally, it would be of interest to determine whether the effects of $\mathrm{NO}_{3}$ - supplementation are additive to, or perhaps even synergistic with, the effects of resistance exercise training.

In summary, we have demonstrated that acute ingestion of $13.4 \mathrm{mmol}$ of $\mathrm{NO}_{3-}$, in the form of a concentrated $\mathrm{BRJ}$ supplement, significantly increases maximal knee extensor angular velocity and power in healthy, 65-79 years old men and women. This improvement in muscle function may help offset the declines in functional abilities and hence the quality of life and independence that often accompany aging.

\section{Funding}

This work was supported by the National Institutes of Health (grant numbers R21 AG053606 to A.R.C., R34 HL138253 to A.R.C. and L.R.P., K23 DK102824 to R.N.M., P30 AR072581 to Sharon Moe, UL1 TR002529 to Anantha Shekhar, and UL1 TR002345 to Bradley Evanoff). The contents of this article are solely the responsibility of the authors and do not necessarily represent the official view of the National Institutes of Health.

\section{Acknowledgments}

This study was designed by A.R.C. and L.R.P.; experiments were performed/ data were collected by all authors; data analysis, interpretation, and manuscript preparation were performed by A.R.C.

\section{Conflicts of Interest}

None.

\section{References}

1. Guralnik JM, Simonsick EM, Ferrucci L, et al. A short physical performance battery assessing lower extremity function: association with selfreported disability and prediction of mortality and nursing home admission. J Gerontol. 1994;49:M85-M94. doi: 10.1093/geronj/49.2.M85.

2. Roshanravan B, Patel KV, Fried LF, et al.; Health ABC study. Association of muscle endurance, fatigability, and strength with functional limitation and mortality in the health aging and body composition study. J Gerontol A Biol Sci Med Sci. 2017;72:284-291. doi: 10.1093/gerona/glw210.

3. Reid KF, Fielding RA. Skeletal muscle power: a critical determinant of physical functioning in older adults. Exerc Sports Sci Rev. 2012;40:4-40. doi:10.1097/JES.0b013e31823b5f13.

4. Maréchal G, Gailly P. Effects of nitric oxide on the contraction of skeletal muscle. Cell Mol Life Sci. 1999;55:1088-1102. doi: 10.1007/ s000180050359.

5. Di Massimo C, Scarpelli P, Di Lorenzo N, Caimi G, di Orio F, Ciancarelli MG. Impaired plasma nitric oxide availability and extracellular superoxide dismutase activity in healthy humans with advancing age. Life Sci. 2006;78:1163-1167. doi: 10.1016/j.lff.2005.06.037.

6. Nyberg M, Blackwell JR, Damsgaard R, Jones AM, Hellsten Y, Mortensen SP. Lifelong physical activity prevents an age-related reduction in arterial and skeletal muscle nitric oxide bioavailability in humans. $J$ Physiol. 2012;590:5361-5370. doi: 10.1113/jphysiol.2012.239053.

7. Richmonds CR, Boonyapisit K, Kusner LL, Kaminski HJ. Nitric oxide synthase in aging rat skeletal muscle. Mech Ageing Dev. 1999;109:177-189. doi:10.1016/S0047-6374(99)00035-4.

8. Proctor DN, Parker BA. Vasodilation and vascular control in contracting muscle of the aging human. Microcirculation. 2006;13:315-327. doi: 10.1080/10739680600618967.

9. Heffernan KS, Chalé A, Hau C, et al. Systemic vascular function is associated with muscular power in older adults. J Aging Res. 2012;2012:386387. doi: 10.1155/2012/386387.

10. Lundberg JO, Weitzberg E, Gladwin MT. The nitrate-nitrite-nitric oxide pathway in physiology and therapeutics. Nat Rev Drug Discov. 2008;7:156-167. doi: 10.1038/nrd2466.

11. Jones AM, Ferguson SK, Bailey SJ, Vanhatalo A, Poole DC. Fiber typespecific effects of dietary nitrate. Exerc Sport Sci Rev. 2016;44:53-60. doi: 10.1249/JES.0000000000000074.

12. Richards JC, Racine ML, Hearon CM Jr., et al. Acute ingestion of dietary nitrate increases muscle blood flow via local vasodilation during handgrip exercise in young adults. Physiol Rep. 2018;6:e13572, doi:10.14814/ phy2.13572.

13. Kelly J, Fulford J, Vanhatalo A, et al. Effects of short-term dietary nitrate supplementation on blood pressure, $\mathrm{O} 2$ uptake kinetics, and muscle and cognitive function in older adults. Am J Physiol Regul Integr Comp Physiol. 2013;304:R73-R83. doi: 10.1152/ajpregu.00406.2012.

14. Siervo M, Oggioni C, Jakovljevic DG, et al. Dietary nitrate does not affect physical activity or outcomes in healthy older adults in a randomized, cross-over trial. Nutr Res. 2016;36:1361-1369. doi: 10.1016/j. nutres.2016.11.004.

15. Eggebeen J, Kim-Shapiro DB, Haykowsky M, et al. One week of daily dosing with beetroot juice improves submaximal endurance and blood pressure in older patients with heart failure and preserved ejection fraction. JACC Heart Fail. 2016;4:428-437. doi: 10.1016/j.jchf.2015.12.013.

16. Shaltout HA, Eggebeen J, Marsh AP, et al. Effects of supervised exercise and dietary nitrate in older adults with controlled hypertension and/or heart failure with preserved ejection fraction. Nitric Oxide. 2017;69:7890. doi: 10.1016/j.niox.2017.05.005.

17. Hirai DM, Zelt JT, Jones JH, et al. Dietary nitrate supplementation and exercise tolerance in patients with heart failure with reduced ejection 
fraction. Am J Physiol Regul Integr Comp Physiol. 2017;312:R13-R22. doi: 10.1152/ajpregu.00263.2016.

18. Coggan AR, Leibowitz JL, Kadkhodayan A, et al. Effect of acute dietary nitrate intake on maximal knee extensor speed and power in healthy men and women. Nitric Oxide. 2015;48:16-21. doi: 10.1016/j. niox.2014.08.014

19. Coggan AR, Broadstreet SR, Mikhalkova D, et al. Dietary nitrate-induced increases in human muscle power: high versus low responders. Physiol Rep. 2018;6:e13575, doi:10.14814/phy2.13575.

20. Coggan AR, Leibowitz JL, Spearie CA, et al. Acute dietary nitrate intake improves muscle contractile function in patients with heart failure: a double-blind, placebo-controlled, randomized trial. Circ Heart Fail. 2015;8:914-920. doi: 10.1161/CIRCHEARTFAILURE.115.002141.

21. Rimer EG, Peterson LR, Coggan AR, Martin JC. Increase in maximal cycling power with acute dietary nitrate supplementation. Int J Sports Physiol Perform. 2016;11:715-720. doi: 10.1123/ijspp.2015-0533.

22. Ferguson SK, Holdsworth CT, Wright JL, et al. Microvascular oxygen pressures in muscles comprised of different fiber types: impact of dietary nitrate supplementation. Nitric Oxide. 2015;48:38-43. doi: 10.1016/j.niox.2014.09.157.

23. Lexell J. Human aging, muscle mass, and fiber type composition. J Gerontol A Biol Sci Med Sci. 1995;50 Spec No:11-16. doi: 10.1093/ gerona/50a.special_issue.11.

24. Coggan AR, Spina RJ, King DS, et al. Histochemical and enzymatic comparison of the gastrocnemius muscle of young and elderly men and women. J Gerontol. 1992;47:B71-B76. doi:10.1093/geronj/47.3.B71.

25. Li L, Wang $\mathrm{H}, \mathrm{Hu} \mathrm{L}$, et al. Age associated decrease of sialin in salivary glands. Biotech Histochem. 2018;93:505-511. doi: 10.1080/10520295.2018.1463453

26. Marzani B, Felzani G, Bellomo RG, Vecchiet J, Marzatico F. Human muscle aging: ROS-mediated alterations in rectus abdominis and vastus lateralis muscles. Exp Gerontol. 2005;40:959-965. doi: 10.1016/j. exger.2005.08.010.

27. Harbo T, Brincks J, Andersen H. Maximal isokinetic and isometric muscle strength of major muscle groups related to age, body mass, height, and sex in 178 healthy subjects. Eur J Appl Physiol. 2012;112:267-275. doi: 10.1007/s00421-011-1975-3.

28. Webb DJ, Freestone S, Allen MJ, Muirhead GJ. Sildenafil citrate and blood-pressure-lowering drugs: results of drug interaction studies with an organic nitrate and a calcium antagonist. Am J Cardiol. 1999;83(5A):21C-28C. doi:10.1016/S0002-9149(99)00044-2.
29. Lundberg JO, Weitzberg E, Lundberg JM, Alving K. Intragastric nitric oxide production in humans: measurements in expelled air. Gut. 1994;35:1543-1546. doi: 10.1136/gut.35.11.1543.

30. Obach RS, Huynh P, Allen MC, Beedham C. Human liver aldehyde oxidase: inhibition by 239 drugs. J Clin Pharmacol. 2004;44:7-19. doi: 10.1177/0091270003260336.

31. Govoni M, Jansson EA, Weitzberg E, Lundberg JO. The increase in plasma nitrite after a dietary nitrate load is markedly attenuated by an antibacterial mouthwash. Nitric Oxide. 2008;19:333-337. doi:10.1016/j. niox.2008.08.003.

32. Thompson BJ, Conchola EC, Palmer TB, Stock MS. Effects of aging on maximal and rapid velocity capacities of the leg extensors. Exp Gerontol. 2014;58:128-131. doi: 10.1016/j.exger.2014.07.019.

33. Miller MS, Bedrin NG, Callahan DM, et al. Age-related slowing of myosin actin cross-bridge kinetics is sex specific and predicts decrements in whole skeletal muscle performance in humans. J Appl Physiol. 2013;115:10041014. doi: 10.1152/japplphysiol.00563.2013.

34. Pojednic RM, Clark DJ, Patten C, Reid K, Phillips EM, Fielding RA. The specific contributions of force and velocity to muscle power in older adults. Exp Gerontol. 2012;47:608-613. doi: 10.1016/j.exger.2012.05.010.

35. Mancini DM, Coyle E, Coggan A, et al. Contribution of intrinsic skeletal muscle changes to ${ }^{31} \mathrm{P}$ NMR skeletal muscle metabolic abnormalities in patients with chronic heart failure. Circulation. 1989;80:1338-1346.

36. Carlström M, Lundberg JO, Weitzberg E. Mechanisms underlying blood pressure reduction by dietary inorganic nitrate. Acta Physiol (Oxf). 2018;224:e13080. doi: 10.1111/apha.13080.

37. Jajja A, Sutyarjoko A, Lara J, et al. Beetroot supplementation lowers daily systolic blood pressure in older, overweight subjects. Nutr Res. 2014;34:868-875. doi: 10.1016/j.nutres.2014.09.007.

38. Hughes WE, Ueda K, Treichler DP, Casey DP. Effects of acute dietary nitrate supplementation on aortic blood pressure and aortic augmentation index in young and older adults. Nitric Oxide. 2016;59:21-27. doi:10.1016/j.niox.2016.06.007.

39. Siervo M, Lara J, Jajja A, et al. Ageing modifies the effects of beetroot juice supplementation on 24-hour blood pressure variability: an individual participant meta-analysis. Nitric Oxide. 2015;47:97-105. doi:10.1016/j. niox.2015.04.007.

40. Coggan AR, Peterson LR. Dietary nitrate influences the contractile properties of human muscle. Exerc Sport Sci Rev. 2018;46:254-261. doi:10.1249/JES.0000000000000167. 